\title{
Information technology tools for the valorisation of seismology's historical documentary heritage
}

\author{
Gabriele Tarabusi $\left({ }^{1}\right)$ and Graziano Ferrari $\left({ }^{2}\right)$ \\ (1) SGA Storia Geofisica Ambiente, Bologna, Italy \\ ${ }^{(2)}$ Istituto Nazionale di Geofisica e Vulcanologia, Bologna, Italy
}

\begin{abstract}
In the past few decades historical documentation of a scientific and non-scientific nature has taken on critical importance in the different sectors of seismology: historical seismology and historical seismometry.

Modern technologies offer unique opportunities for cataloguing and efficiently distributing the reproductions or digital versions of scientific letters.

Over the last 20 years SGA (Storia Geofisica Ambiente) has set up and promoted, within the scope of the TROMOS (INGV-SGA) and EUROSEISMOS (INGV-SGA) projects, initiatives for the cataloguing, reproduction, study and dissemination of documentation relating to the history of seismology in both Italy and Europe. This approach, based on the application of modern technologies, has enabled us to achieve a rigorous processing and study of documents using the most appropriate information technology tools.

The techniques we have used encourage the dissemination and study of historical scientific documentation seeking to bring together scholars and research groups within a new disciplinary community dedicated to studying the history of earth sciences.
\end{abstract}

Key words history of seismology - historical documentation - information technology - historical database - Tromos - Euroseismos

\section{Introduction}

Over the last few decades, historical documentation, both of a scientific and non-scientific nature, has acquired critical importance in the different sectors of seismology: i.e. historical seismology and historical seismometry. Apart from the undisputed cultural and historical value of the testimonies concerning the Ital-

Mailing address: Dr. Gabriele Tarabusi, SGA Storia Geofisica Ambiente, Via Fioravanti 59/2, 40129 Bologna, Italy; e-mail: tarabusi@sga-storiageo.it ian historical earthquakes and the documentation of the long Italian seismological tradition (Ferrari, 1997), multidisciplinary methodological approaches to the study of past earthquakes have been taking shape, both from the macroseismic and the instrumental standpoints (Boschi et al., 2000; Guidoboni et al., 2007).

In these innovative study sectors, Italy has been a very important laboratory for methodological experimentation. The literature on the methodology and the results of these approaches are broad and consolidated. This paper analyses the contribution of the modern technologies to the valorisation and the dissemination of the historical-scientific materials on seismology and the products of their elaboration.

Among the most interesting materials, the epistolary documentation of a conventional scientific kind stand out together with specialised documents (macroseismic questionnaires). In- 


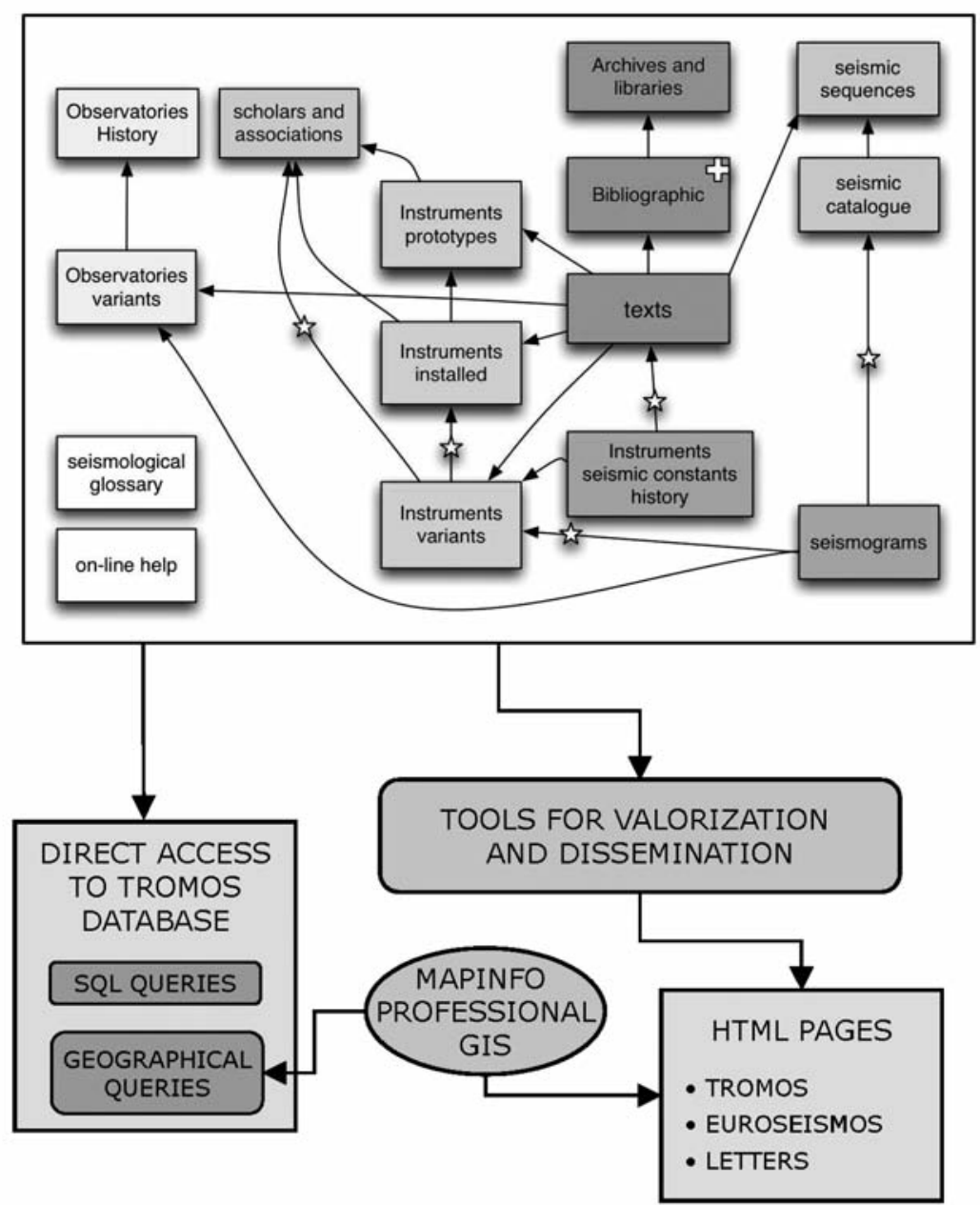

Fig. 1. Simplified scheme of the structure of the TROMOS database and the relations between the different files. Although it can be managed in a relational way, in this case a hierarchical structure of the links has been preferred. The levels of the hierarchy correspond to the respective positions of the files in the figure. In particular, for the observatories there are two files: the one of the observatory's history, in which all the information is summarised as well as the history of the observatory and the file of its variants (name, location, etc.).

As regards the instruments, there are three files connected with one another: the file of the prototypes (the idea and the description of the instrument even if never actually made), that of the instruments actually made and located in the observatories and the file of the variants of the instruments devised (modifications, re-location etc.). One file collects the information related to scholar and the association. Two files collect the information relating to the earthquakes: one relating to the whole sequence and one relating to each earthquake that is the reference for the file cataloguing the seismograms.

The bibliographic file with the related texts of the sources and the information relating to the archive or the library of conservation, guarantees the documentary support to the information contained in the variation files on observatories, instrument variants, prototypes, scholars, seismic sequences, and seismological glossary.

The database is potentially set up for sharing its files with other complementary files such as the CFTI4Med (Guidoboni et al., 2007) is indicated on the right of the figure. Different types of interface and interactions with other information technology tools allow for the use of the data in different modalities and a wide range of scientific and cultural users. 


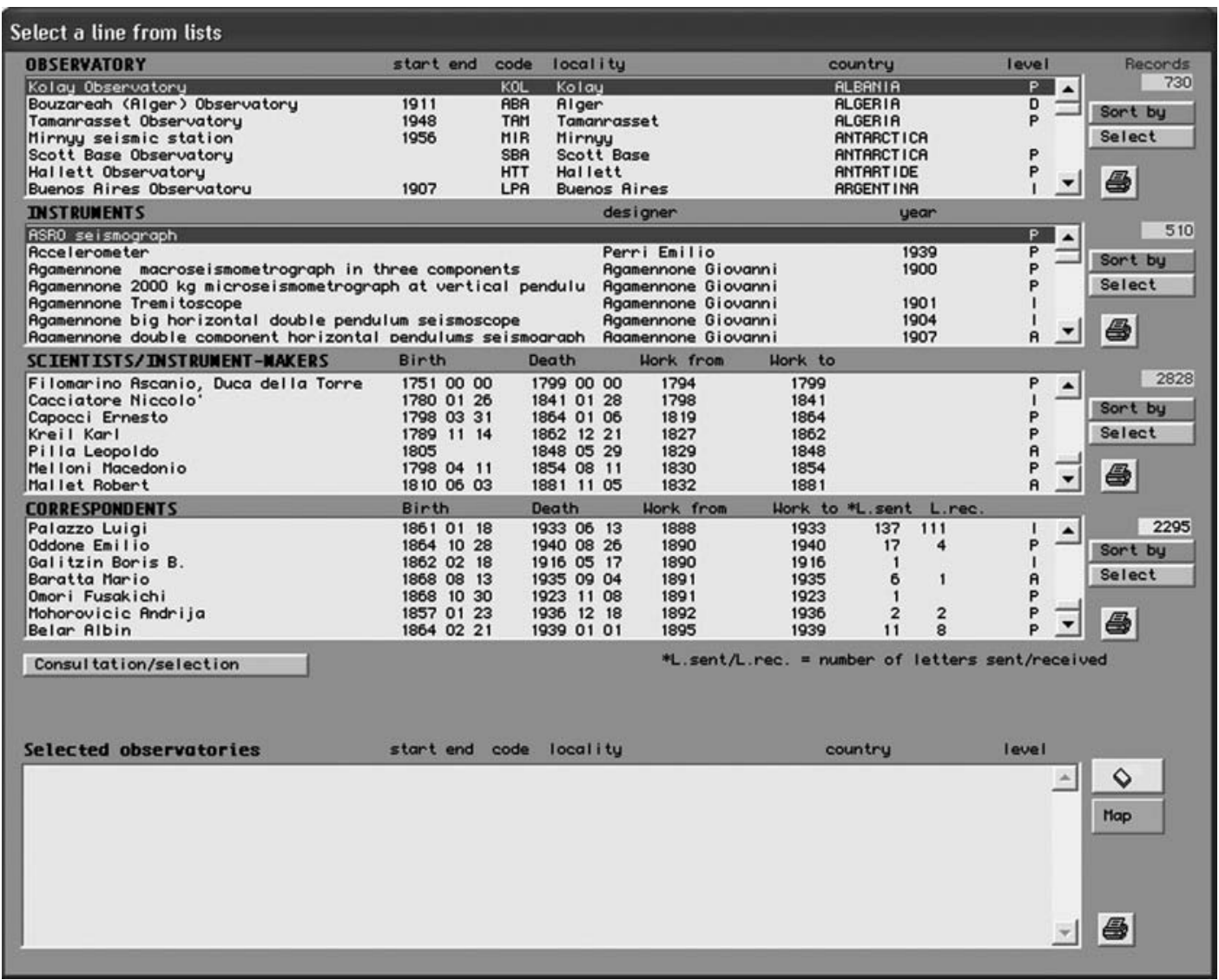

Fig. 2. The main consultation window of the TROMOS database contains four lists with summary information: observatories, instruments, scholars/builders/associations, epistolary correspondents catalogued in the database. A fifth list, at the bottom, is dedicated to collecting a selection of observatories, activated by double-clicking one ach line of interest of the observatories list, following activation of the button: «Consultation/selection». A click on the button «Map» allows us to create a map with the localisation of the selected observatories. Double-clicking on each line of the list activates a specific detail window.

deed, it is important from the scientific standpoint both in itself and as a complementary document to the seismological data sensu stricto (i.e. seismic recordings, seismological observations, etc.).

\section{The TROMOS Project}

Over the last 20 years SGA has performed and/or coordinated research and processed data within the scope of historical seismometry studies and the history of seismology in Italy (TROMOS project) and Europe (ESC Working Group History of Seismometry) (Ferrari, 1997).

Started by ING in 1990, the TROMOS project has been addressed to the research, recovery, restoration and re-establishment of the historical heritage of Italian seismology. The results of TROMOS (1990-2007) project in Italy have led European Seismological Commission to establish the Working Group «History of 


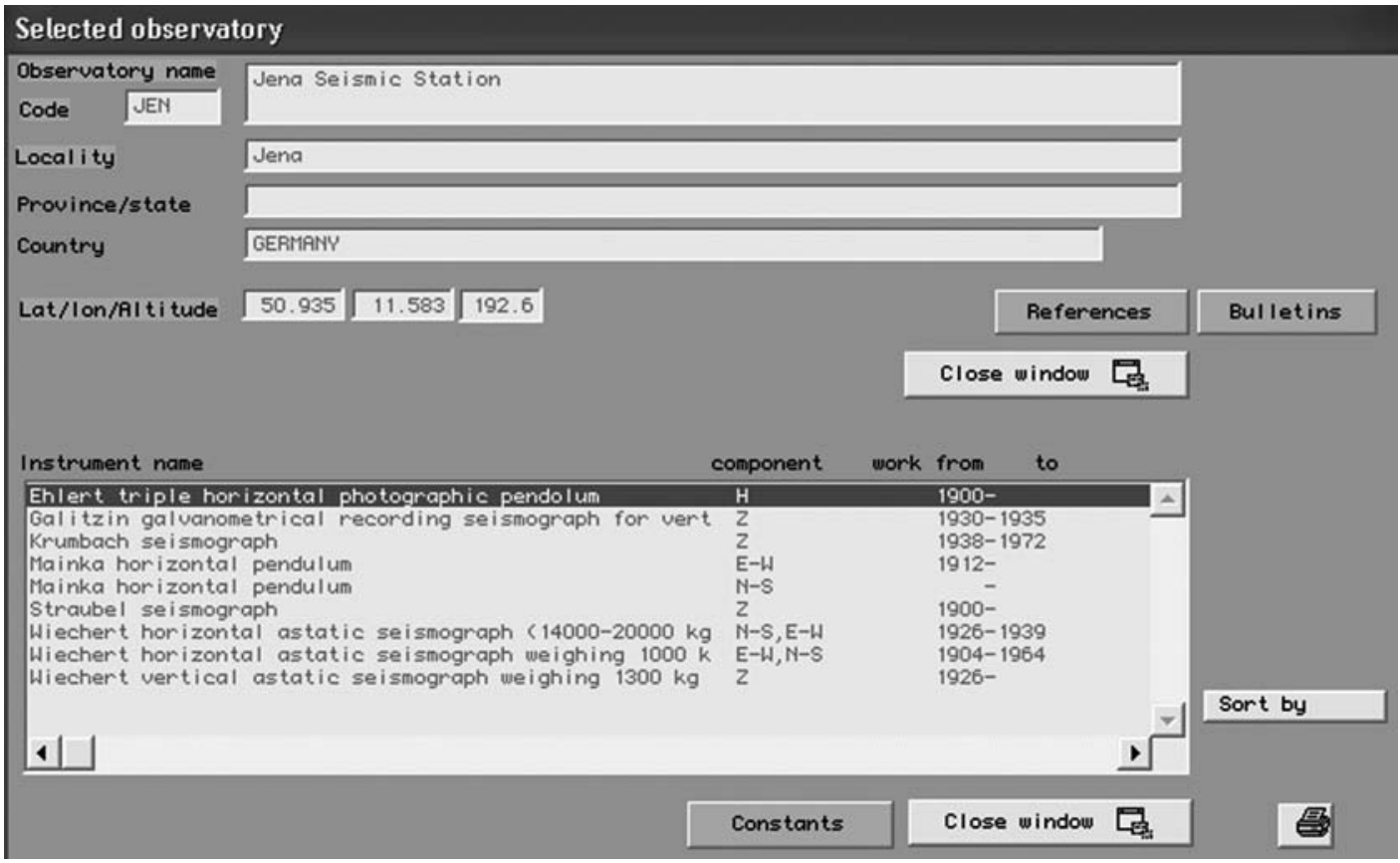

Fig. 3. Observatories file, example of record. The following are indicated: name, international code, location, province or region, country, geographical coordinates and quota.

The button «Bulletins» open the window with the list of all the bulletins present in the data base, relating to the selected observatory (fig. 5).

In the lower part of the window there is, only when the data are available, the list of instruments used in the observatory, present in the data base. When available these report, besides the name of the instrument, also the components and the start and end dates of function. With the button 'Constants', the window Instrument constants is accessed, which allows for the visualisation of all the characteristics of the selected instruments, which in turn allows for access to the consultation window of the constant history of the instrument (fig. 7).

Seismometry» (WG HoS) in 1992. During its 17 years of activity the project's chief aims were:

- the listing of the Centres of meteorological and seismic observation operating in Italy (18th-20th century), with details of the current whereabouts of the relevant materials and historical instruments;

- the restoration of some of the most important historic seismic instruments in the Italian meteorological and seismological observatories;

- the recovery and restoration of the historical seismograms of strong Italian earthquakes recorded from the late 19th century in Italian and European centres;
- the dissemination of the historic and scientific results of the research performed.

A dedicated indexing system has been set up to store the information gathered from the systematic collection and analysis of both published and unpublished contributions found in the course of the research.

A dedicated database (Ferrari, 1992), developed by SGA on behalf of the Istituto Nazionale di Geofisica e Vulcanologia, has been designed for the electronic storage of the indexed information (fig. 1). Thanks to the long experience of SGA in the research and electronic storage of all kinds of environmental history data, the database, after its first release, was up- 


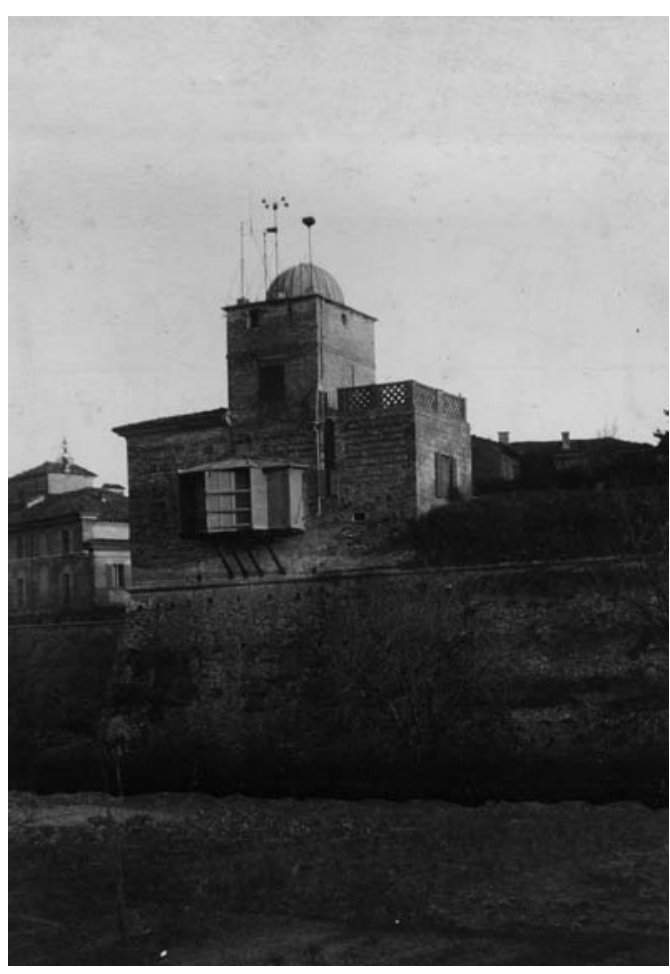

Fig. 4. Observatories file, example of iconography Valerio meteoric-magnetic observatory in Pesaro. dated «on the field». The current state of the database has been verified after 16 years of improvement in the rationale and the efficiency of its structure and tools (figs. 2-9).

The research numbers can be summed up as follows: 15,000 bibliographic and documentary sources (17th-20th century) have been found; they concern over 1,000 meteorological and seismological observatories, over 600 instruments and 250 instrument-makers; 5,000 of these sources have been entered in the database. Over 5,000 letters have so far been individually and partly microfilmed and analyzed.

Approximately 70 historic centers with an observational tradition from the 1,200 catalogued ones have been visited or examined; about 150 instruments (from 1818 to the 1970s) out of the 600 ones registered in the database have been identified and photographed.

Apart from valorising the fundamental contribution of the Italian scientific community to world seismology, the research performed within the scope of the TROMOS project and the related specialist and non-specialist scientific products developed (books, data base and internet web site) have allowed us to outline and create a relatively accurate picture of the consistency and the state of preservation of the instru-

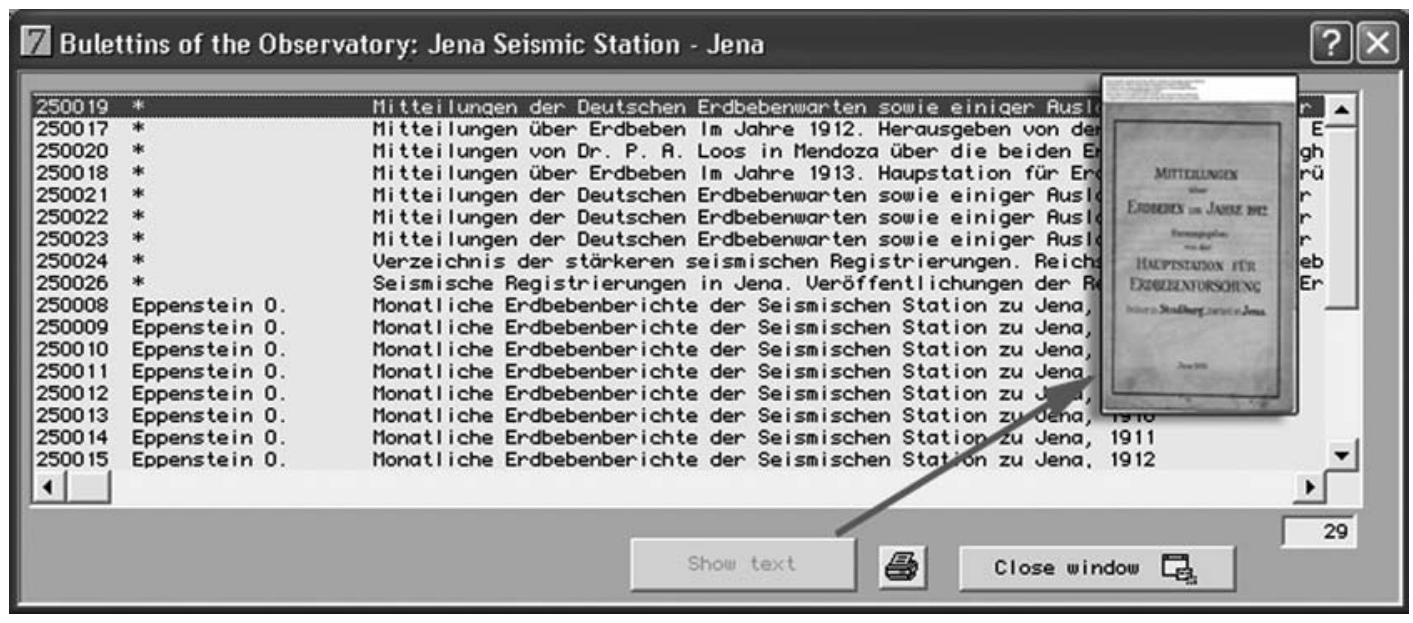

Fig. 5. Bulletins file, consultation window of all the bulletins present in the data base, relating to the selected observatory. By highlighting a record from the list of bulletins it is sufficient to press the button «Show text» to open the PDF file containing the digital scan of the original text. 


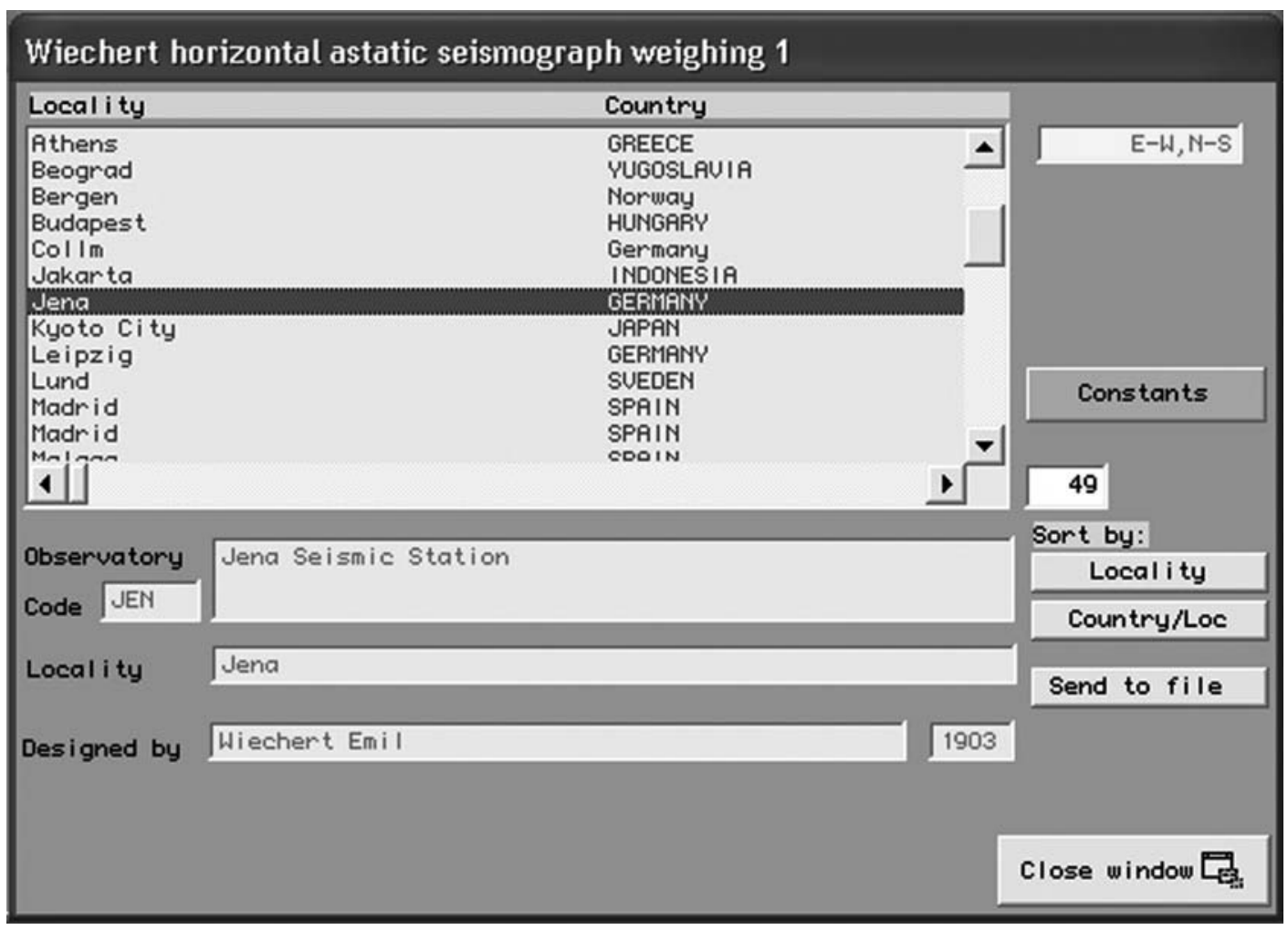

Fig. 6. Instruments file, example of record relating to the dissemination of the $1,000 \mathrm{~kg}$ Wiechert astatic horizontal seismograph. By double-clicking on a line of the list you can access the detail of the information on that specific instrument. Highlighting a record from the list of bulletins it is enough to press the button Constants to access the window Instrument constants, which allows the visualisation of all the characteristics of the selected instrument and that in turn allows for the access to the consultation window of the constant history of the instrument (fig. 7).

ments and historical scientific documentary materials of the Italian seismological observatories that operated from the 1850 s until the 1970s. The most recent investigations have shown a worrying increase in the risk of dispersion of these assets. Among these materials the station log book, scientific letters, seismograms, particularly rare Italian and foreign seismic bulletins stand out. In other cases, documentary files very important for seismology are inaccessible or hard to trace unless they are properly classified, reproduced and transcribed. In fact, it is often a matter of handwritten materials that are quite difficult to read and that require a good knowledge of the contextual his- torical seismological and meteorological setting for a complete understanding. Among these scientific materials produced by scholars in earth sciences an important role is played by the scientific letters in the reconstruction of the development of scientific instruments, the methods of inquiry and the scientific theories. Scientific letters between meteorologists and seismologists from the 1850 s quite often contain important scientific data that may be potentially useful even today. In the activity of averting the dispersion and incentivising the wealth of unpublished historical scientific documentation from the important historic meteorological-seismic observatories, starting from 2002 a 


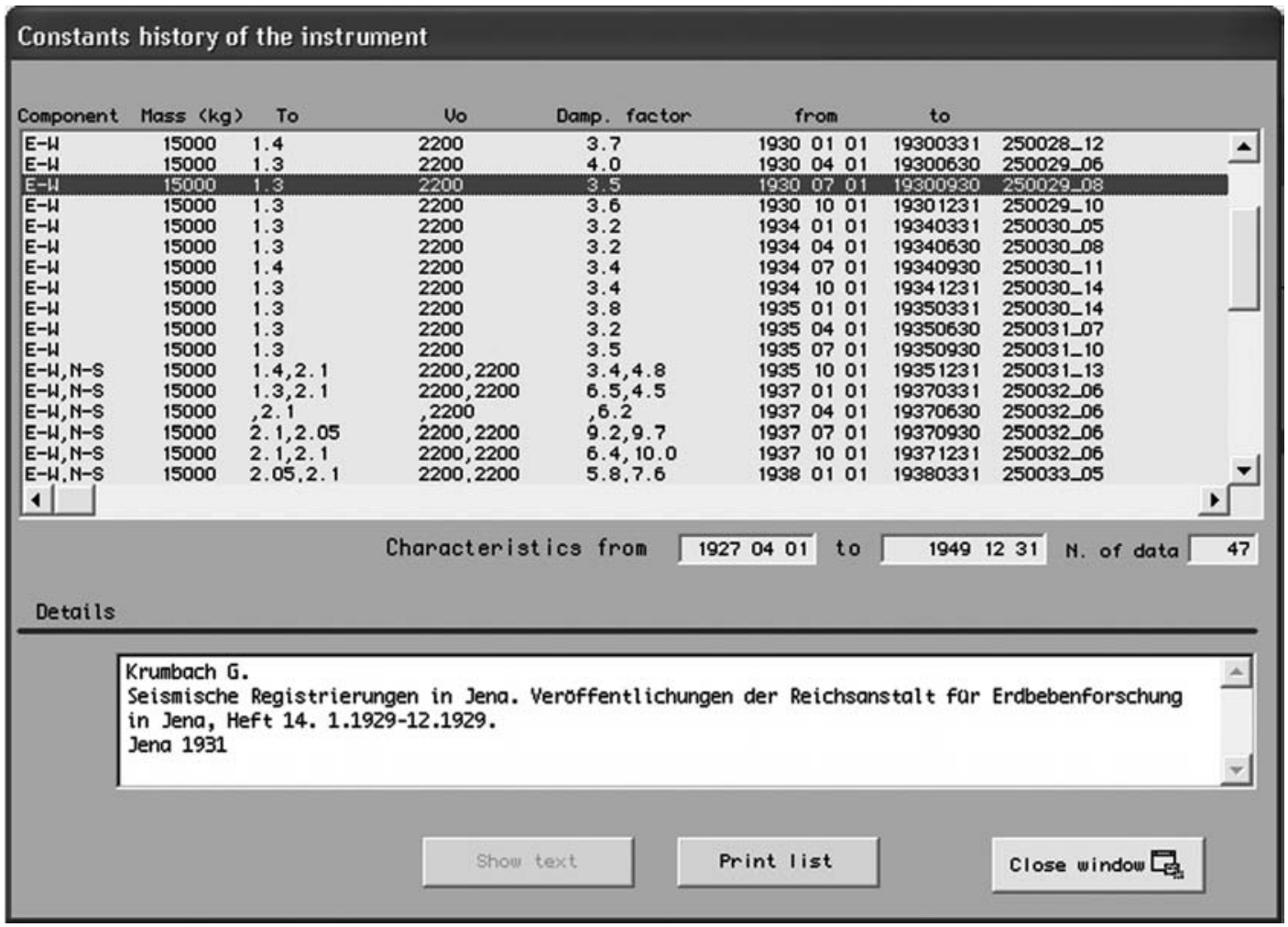

Fig. 7. Instruments seismic constants history file, consultation window of the constant history of the instrument. By selecting a line from the list the related bibliographic reference is highlighted in the text field «Details» at the bottom. By clicking on the button «Show text» the PDF file is opened containing the digital scan of the original text from which the information have been extracted.

specific project of cataloguing and reproduction of scientific correspondence has been launched: Letters in Earth Sciences (Ferrari, 2002).

The research, extended to the broader community of scholars and sites preserving historic materials, aims to promote and foster the identification, cataloguing, electronic scanning and dissemination of files relevant to the history of earth sciences and astronomy.

At the same time the project also attempts to promote the recovery, in digital format, of everything hitherto published: letter catalogues, registries and whole letter transcriptions: digital document scanning should also support this phase. In this phase the project leaders are mak- ing contact with the various institutions that preserve historical correspondence having some relevance for this research, already partly transferred into printed materials, to sound out their willingness to collaborate.

Cataloguing, scanning and dissemination are carried out in compliance with any copyrights safeguarded by the applicable laws and on the grounds of any agreements signed with bodies or private individuals holding the files relevant to the study.

Within the scope of this project, we have catalogued and scanned the Tacchini correspondence archives held at the Ufficio Centrale di Ecologia Agraria (Central Office of Agrarian 


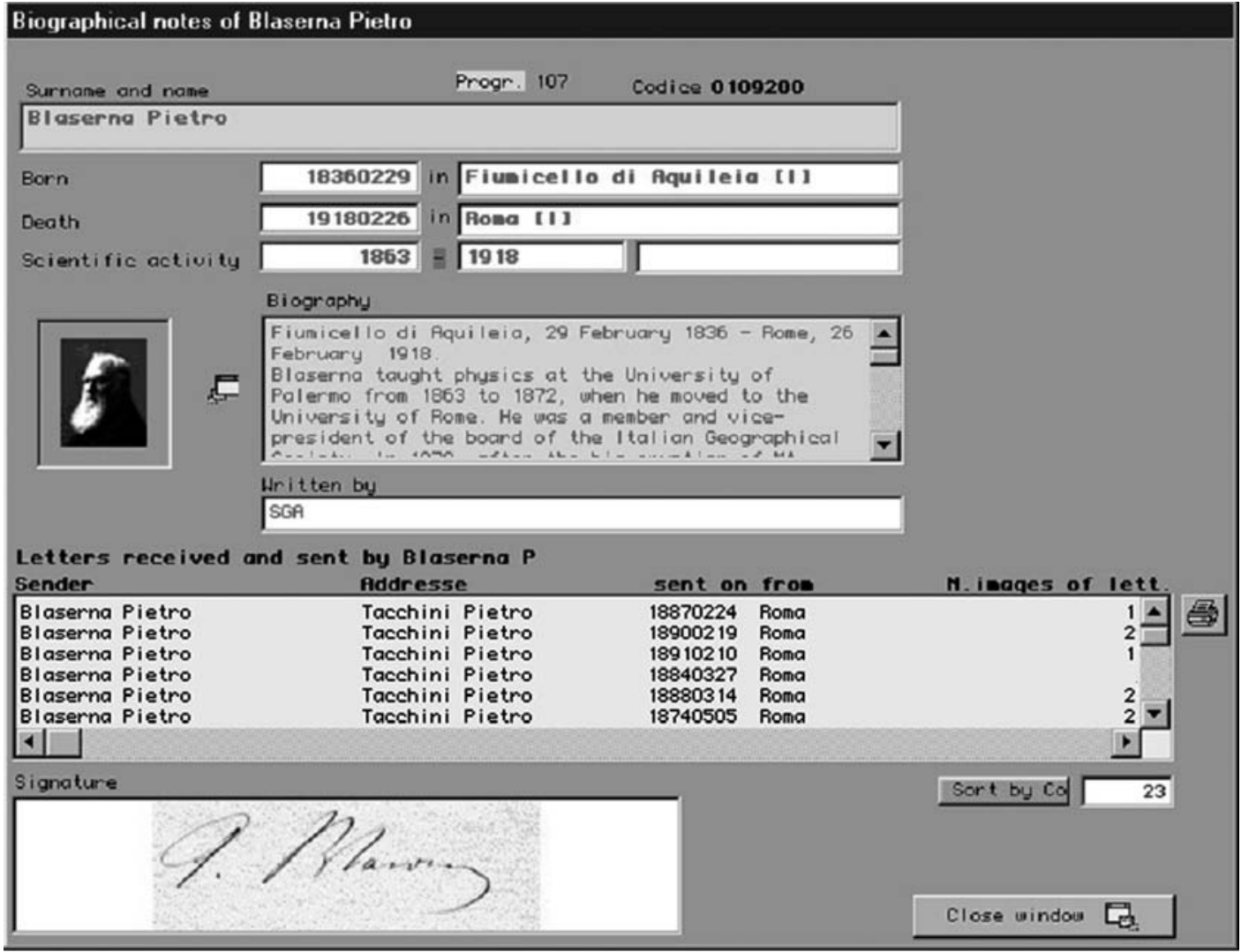

Fig. 8. Scholars and associations file, example of record. Apart from the biographical information, the window reports the list of the letters sent or received by the scholar. Double clicking on the line of interest opens a window with the details of the related letter, also with the chance to open the PDF file of the integral raster reproduction of the letter.

Ecology, Rome) and the Grablovitz Archive at Ischia, only recently made available by the heirs.

The Tacchini correspondence archives, crucially important for the history of seismology, comprise about 5,100 letters from one of the most important periods for seismology (from 1861 to 1900), during which the Italian geodynamic service started taking shape, the forerunners of the geophysical network of the Istituto Nazionale di Geofisica. For this archive the cataloguing has been completed followed by the digital reproduction of the correspondence having a historical seismological interest. The let- ter archive of Giulio Grablovitz at Ischia was first of all catalogued and subsequently the digital reproduction of the correspondence having a prevalent seismological and meteorological interest was performed, for over 1,000 letters altogether, while the seismograms were restored and made available to the SISMOS Centre for high-resolution digital scanning.

A website (http://storing.ingv.it/letters/) has also been set up. The site allows for the selection of project database subsets by the name of the correspondents and by date-intervals (fig. 10). Also being set up is a GIS interface that 


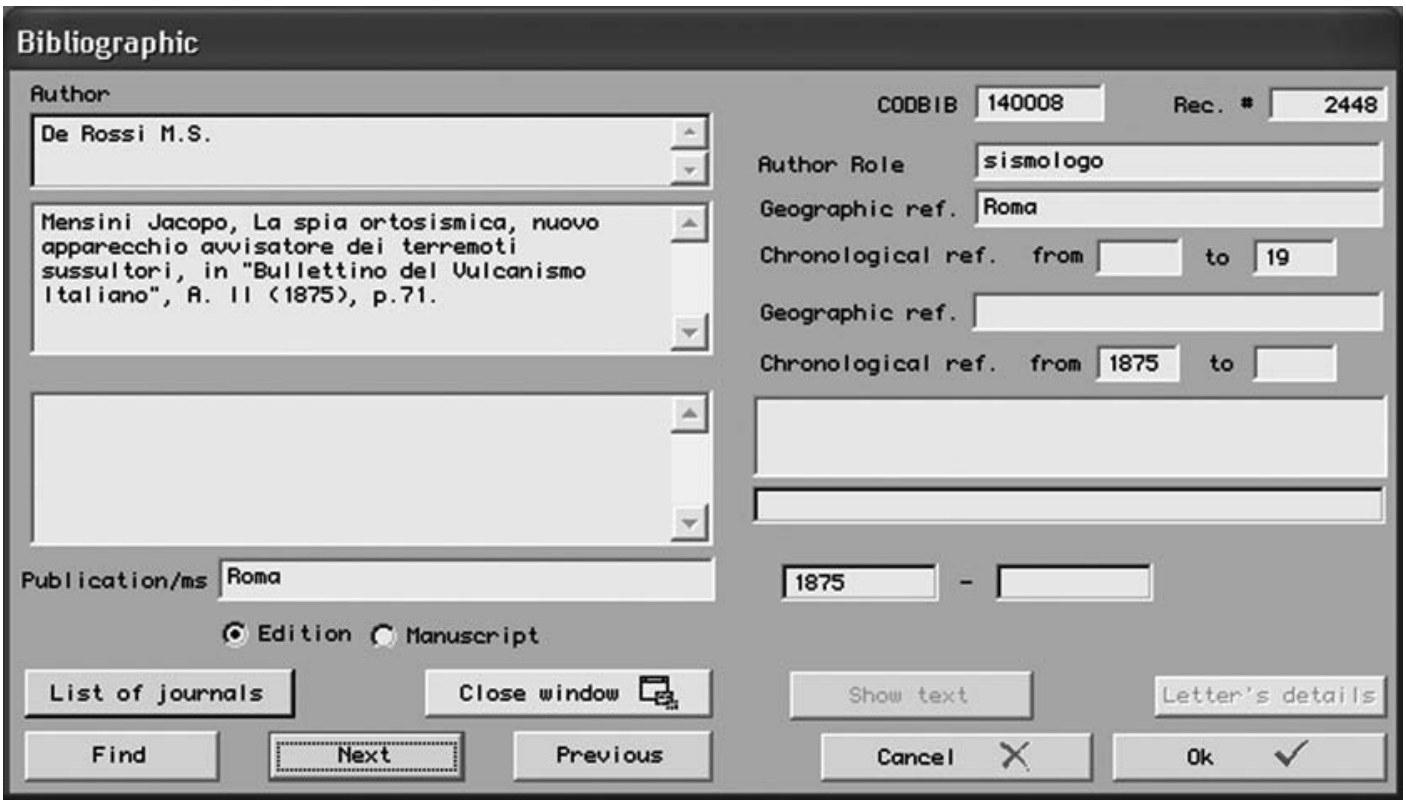

Fig. 9. Bibliographic file, main search window. In this file different kind of printed and manuscript documents (observatories, instruments, scholars, earthquakes etc.) are stored: selected papers from scientific journals, books, station bulletins, station handbooks, letters etc.

Each chart reports the bibliographic code (CODBIB) and the progressive order of the document and, if available at the current state of the research, the following information: name, role, geographical and chronological reference of the author; title, geographic and chronological reference of the document; the place and date of the publication; whether it is a publication, a manuscript or a copy of a manuscript.

In the case of scientific correspondence, if further information is available for a letter, a button named «Letter Details» is activated, which, once pressed, opens the window with the details of the related letter, and the chance to open the PDF file of the integral raster reproduction of the letter

will allow for the geographical querying of the online database.

\section{The EUROSEISMOS Project}

Digital preservation of the unique seismological patrimony consisting of historical seismograms and earthquake bulletins, and of related documentation (e.g., observatory log books, station books, etc.), is of utmost importance to avoid deterioration and loss over time (Kanamori, 1988). Dissemination of this seismological material in digital form is of equal importance to allow for the re-evaluation of past earthquakes using modern techniques and the re-evaluation of the seismic hazard.

In 2002 at the ESC held in Genoa, a project entitled «Saving and Studying the Seismograms of the Strongest Euro-Mediterranean Earthquakes» coordinated by Graziano Ferrari (SGA - Storia Geofisica Ambiente) and Nicola Alessandro Pino (Istituto Nazionale di Geofisica e Vulcanologia, INGV) was started. The project was named EuroSeismos (ES) and initially saw the participation of 24 researchers belonging to 15 countries which then grew to more than 40 researchers belonging to 31 countries from the Euro-Mediterranean area.

The goal of the project was to exploit fully 


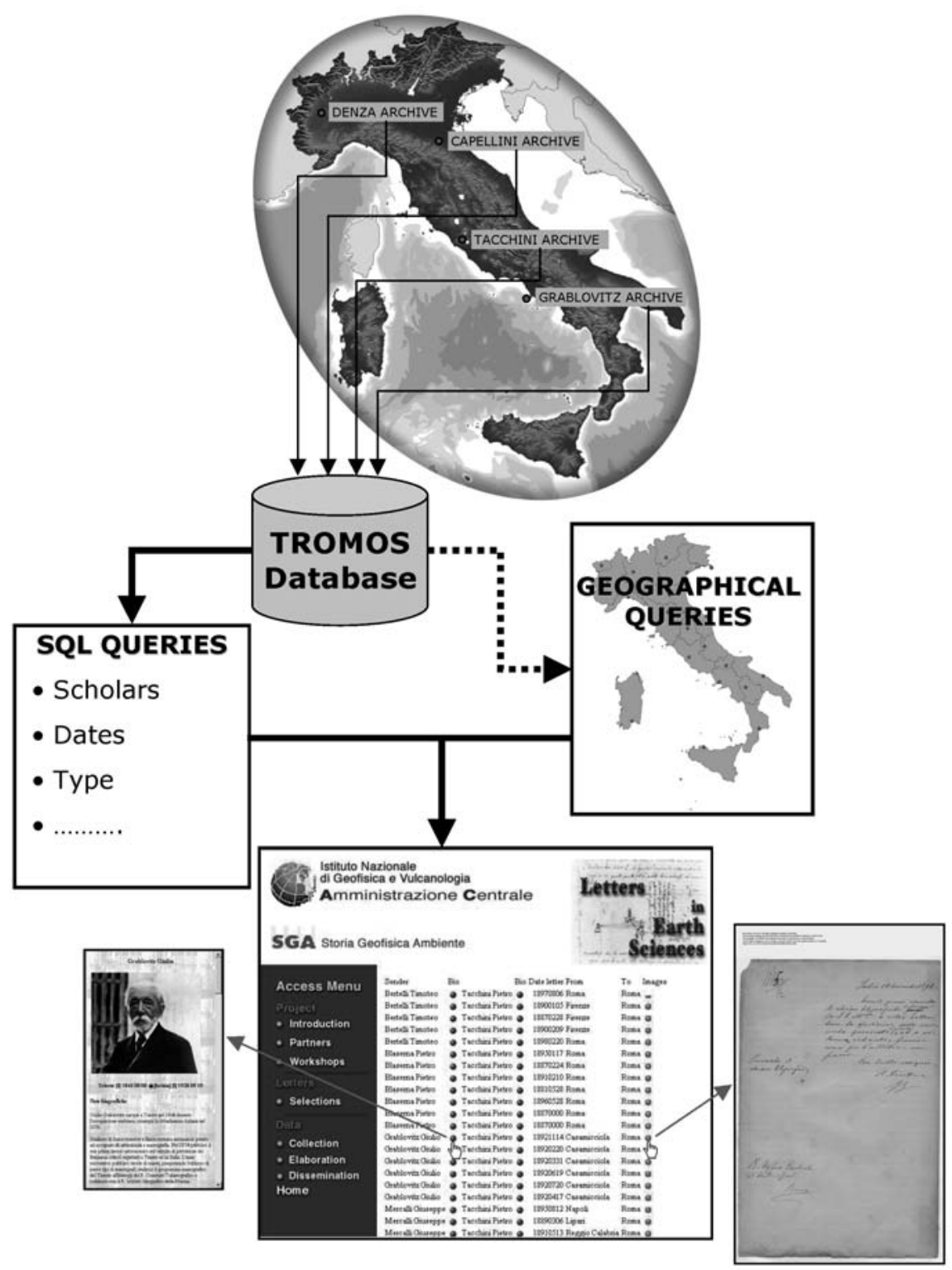

Fig. 10. Simplified scheme of the process of acquisition and dissemination materials of the project Letters in Earth Sciences. The letters processed in different forms (digital scanning, full transcription, registry) from the original place of preservation are catalogued and all the papers are added to the TROMOS database. The internet-based dissemination project of all the materials provides for the parametric (i.e. the name of the correspondents, chronological range, type of letter and contents, etc.) as well as geographical querying of the database. The first type of querying has already been set up, while the geographical type of approach is still undergoing completion.

At the bottom, an example of the outputs list. The keys to the right of the correspondents' names refer back to their respective biographies, while the button on the far right refers back to the image of the letter and the correlated information. 

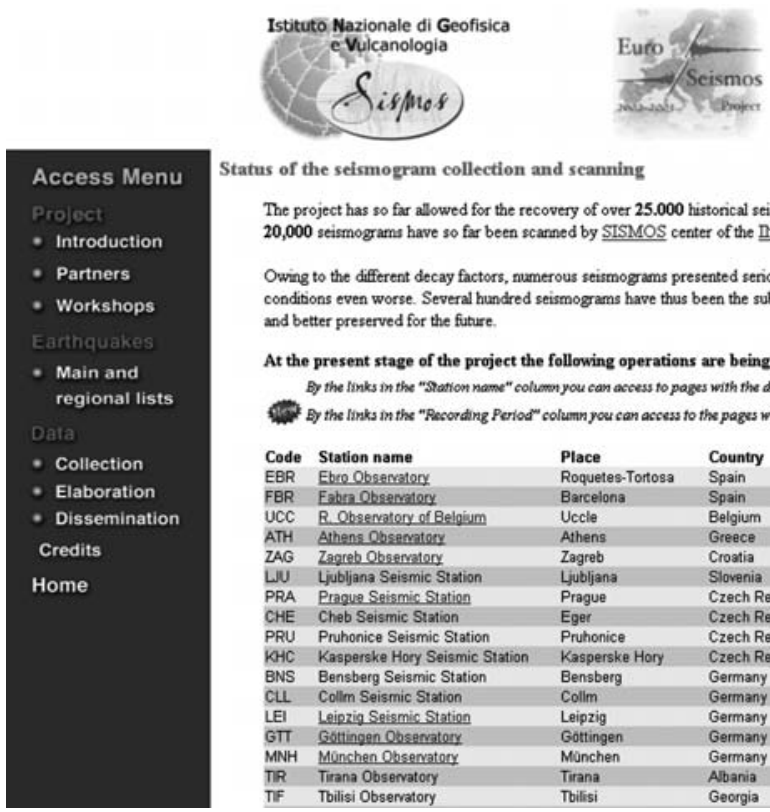

SGA Storia Geofisica Ambiente

Status of the seismogram collection and scanning

The project has so far allowed for the recovery of over 25.000 histonical seismograms from 126 observatories of 28 of the 29 countries that have joined the project. Over 20,000 seismograms have so far been scanned by SISMOS center of the DNGV.

Owing to the different decay factors, numerous seismograms presented serious preservation problems and handling them could have made their already precanious conditions even worse. Several hundred seismograms have thus been the subject of conservative and integrative restoration work, so that they could be digtally scanned and better preserved for the future.

At the present stage of the project the following operations are being organised and scheduled as in the table below.

By the tinks in the "Station name" collumn you can access to pages with the data available for the Station

10. By the links in the "Recording Period" column you can access to the pages with the list of scarned Strmograms avallable from each Station.

\begin{tabular}{|c|c|c|c|c|c|c|c|c|}
\hline Code & Station name & Place & Country & Responsible & $\begin{array}{l}\text { Recording } \\
\text { period" }\end{array}$ & $\begin{array}{l}\text { Transfer to } \\
\text { Italy }\end{array}$ & Arrived & $\begin{array}{l}\text { Present } \\
\text { state }\end{array}$ \\
\hline EBR & Ebro Obsensatory & Roquetes-Tortosa & Spain & J.Batllo & $1904-1966$ & -022003 & 03032003 & returned \\
\hline FBR & Eabri ebrenatery & Barcelona & Spain & J.Batllo & $1906-1990$ & -022003 & 03.03 .2003 & retumed \\
\hline UCC & R. Obsenatory of Belgium & Uccle & Belgium & T.Camelbeeck & $1909-1963$ & -062003 & 04.062003 & returned \\
\hline ATH & Athens Obsematery & Athens & Greece & L.Baskoutas & 1912.1976 & -062003 & 22062003 & scanned \\
\hline ZAG & Zagreb Obsemstory & Zagreb & Croatia & LAllegretti & $1907-1983$ & -072003 & 22082003 & retumed \\
\hline LUU & Ljubljana Seismic Station & Ljubljana & Slovenia & M Znvic & $1960-1990$ & -082003 & 06082003 & refumed \\
\hline PRA & Prague Seismic Station & Prague & Czech Republic & JZednik & $1928-1957$ & -082003 & 06082003 & retumed \\
\hline CHE & Cheb Seismic Strtion & Eger & Czech Republic & JZednik & $1909-1957$ & -082003 & 06.082003 & retumed \\
\hline PRU & Pruhonice Seismic Station & Pruhonice & Czech Republic & JZednik & $1958-1999$ & -082003 & 06.08 .2003 & retumed \\
\hline $\mathrm{KHC}$ & Kasperske Hory Seismic Station & Kasperske Hory & Czech Republic & JZednik & 1951.1992 & -08.2003 & 06082003 & retumed \\
\hline BNS & Bensberg Seismic Station & Bensberg & Germany & D.Kaiser & $1953-1980$ & -012004 & 19.01 .2004 & returned \\
\hline $\mathrm{cLL}$ & Collm Seismic Station & Collm & Germany & D. Kaiser & $1956-1960$ & -012004 & 1901.2004 & retumed \\
\hline LEI & Leiprig Seismic Station & Leipzig & Germany & D.Kaiser & $1911-1964$ & -01.2004 & 19.01 .2004 & retumed \\
\hline Gा & Gettingen Obsematery & Gottingen & Germany & D.Kaiser & $1904-1980$ & -01.2004 & 19.01 .2004 & returned \\
\hline MNH & München Observatory & Müchen & Germany & D.Kaiser & $1905-1990$ & -012004 & 19.01 .2004 & retumed \\
\hline$\pi R$ & Tirana Obsenatory & Tirana & Abania & LDuni & $1909-1900$ & -092003 & 1209.2003 & retumed \\
\hline$\pi F$ & Tbilisi Observatory & Tbilisi & Georgia & M.Elashvili & $1913-1976^{\circ}$ & -022004 & -022004 & returned \\
\hline
\end{tabular}

Fig. 11. «Collection» section of the ES Website with progressive updating of the phases that have affected the seismograms coming from the different partner countries involved in the project.

\section{Seismograms available from Göttingen Obsenvatory - Germany}

\begin{tabular}{|c|c|c|c|c|c|c|c|}
\hline Preview* & $E S^{* *}$ & COD COMPL & Instrument & COMP & To & Vo & Earthquake \\
\hline 8 & ES & OTT_E_1904071307141 & Wiechert & $E, N$ & $14.00 ; 10.6$ & $151 ; 160$ & 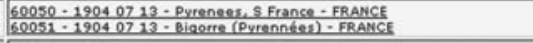 \\
\hline Q & ES & GT_R_L_1904071307141 & Wiechert & $E \leqslant N$ & $14.00: 10.6$ & $151 ; 160$ & 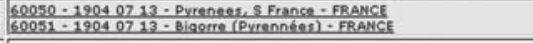 \\
\hline & ES & OTT_N_1904071307141 & Wiechert & $E ; N$ & $14.00 ; 10.6$ & $151 ; 160$ & $\begin{array}{l}60050-19040713 \text { - Pyrenees, S France - FRAALCE } \\
60051-19040713 \text { - Biaorre (Pyrennées) - FRAMCE }\end{array}$ \\
\hline & ES & OTT_N_1905041008421 & Wiechert & $E, N$ & $14.00,10.6$ & 151,160 & 60053 - 190504 - 10 - Vaisen Le Remaine (Vallee Du Rhone) - FRANCE \\
\hline & & OTT_N_1905052807521 & Wiechert & E, N & $14.00 ; 10.6$ & $151 ; 160$ & \\
\hline & & GTT_E_1905052807521 & Wiechert & $E ; N$ & $14.00: 10.6$ & $151 ; 160$ & \\
\hline 4 & & OTT_N_1905052808001 & Wiechert & $\mathrm{N}, \mathrm{E}$ & 1.5 & 2100 & \\
\hline & ES & GTT_E_1905052907561 & Wiechert & $E ; N$ & $14.00: 10.6$ & 151,160 & 60056 - 19050529 - Ivaniciea (Hv Croatia) - CROATIA \\
\hline 舟 & ES & GTT_N_1905090710581 & Wiechert & $E, N$ & $14.00: 10.6$ & $151 ; 160$ & 19344 - 19050908 - Calabria - ITALY \\
\hline Da & Es & 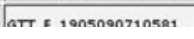 & lwiachant & $\operatorname{lin}_{\mathrm{N} N \mathrm{~N}}$ & 14.nn:1n.2. & $\longdiv { 1 5 1 : 1 < n }$ & 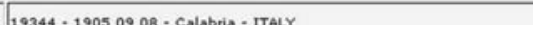 \\
\hline
\end{tabular}

Fig. 12. From the «Seismograms Available» section of the ES Website, it is possible to know for each Observatory the details relating to the scanned seismograms available in the SISMOS web site. From this section it is also possible to have low-resolution preview access of the seismograms, know the mean values of the main instrumentals constants (from the TROMOS database) and know which earthquakes, among those chosen by the project partners, refer to each recording. 


\begin{tabular}{|c|c|c|c|c|c|c|c|c|c|c|c|c|c|c|c|c|}
\hline \multicolumn{17}{|c|}{ Earthquakes requested by Albania } \\
\hline & & & & & & & & & & & & & & & \multicolumn{2}{|c|}{ Download the list in ASCII format } \\
\hline NTERR & ns & $R$ & Year & Mo & $\mathrm{Da}$ & Ho & Mi & Se & Lat & Lon & 10 & $M$ & Prior & Req & Epicentral Zone & Country \\
\hline 60057 & 10 & $\%$ & 1905 & 106 & 01 & 04 & 42 & 19.5 & 42 & 19.5 & 9 & 6.6 & A & Duni - Pekevski & Morthern Albania & Albania \\
\hline 60115 & 38 & $\%$ & 1911 & 02 & 18 & 21 & 35 & 18 & 40.85 & 20.7 & 9 & 6.7 & A & Duni - Pekevski & Ohrid Lake Region & Albania \\
\hline 60189 & 34 & $\%$ & 1920 & 11 & 26 & 08 & 51 & 10 & 40.35 & 19.95 & 9 & 6.4 & A & Duni - Baskoutas & Southern Albania & Albania \\
\hline 60232 & 56 & $\%$ & 1926 & 12 & 17 & 11 & 39 & 50 & 41.3 & 19.5 & 9 & 6.2 & A & Duni - Baskoutas & Central Albania & Albania \\
\hline 60275 & 55 & & 1930 & 11 & 21 & 02 & 100 & 27 & 40.2 & 19.6 & 9 & 6.1 & A & Duni & Southern Albania & Albania \\
\hline 60359 & 65 & $*$ & 1942 & 08 & 27 & 06 & 14 & 11 & 41.65 & 20.45 & 8 & 6 & A & Duni-Pekevski & North-Easter Albania & Albania \\
\hline 60481 & 90 & & 1959 & 09 & 01 & 11 & 37 & 40 & 40.85 & 19.8 & 8.5 & 6.2 & A & Duni & Southern Albania & Albania \\
\hline 60484 & 96 & & 1960 & 05 & 26 & 05 & 10 & 11 & 40.6 & 20.7 & 9 & 6.4 & $A$ & Duni & South-Eastern Albania & Albania \\
\hline 30421 & 111 & $\%$ & 1962 & 03 & 18 & 15 & 30 & 32 & 40.7 & 19.6 & 8 & 6 & A & Duni - Pekevski & Southern Albania & Albania \\
\hline 60498 & 41 & & 1963 & 02 & 22 & 14 & 12 & 51 & 40.2 & 20 & 7 & 5.2 & $B$ & Duni & Southern Albania & Albania \\
\hline 60516 & 141 & $\%$ & 1967 & 11 & 30 & 07 & 23 & 50 & 41.32 & 20.34 & 9 & 6.6 & A & Duni - Pekevski & North-Eastern Albania & Albania \\
\hline 60526 & 86 & & 1969 & 04 & 03 & 22 & 12 & 22 & 40.48 & 19.92 & 7 & 5.6 & $B$ & Duni & Southern Albania & Albania \\
\hline 60538 & 73 & & 1970 & 108 & 19 & 02 & 01 & 53 & 41.15 & 19.6 & 7 & 5.5 & $B$ & Duni & Central Albania & Albania \\
\hline 60561 & 149 & & 1979 & 04 & 15 & 06 & 19 & 41 & 42.16 & 18.87 & 9.5 & 6.9 & A & Duni & Montenegro & rugoslavia \\
\hline 60563 & 161 & & 1979 & 105 & 24 & 17 & 23 & 18 & 42.24 & 18.75 & 8 & 6.4 & A & Duni & Montenegro & rugoslavia \\
\hline 60570 & 49 & & 1982 & 11 & 16 & 23 & 41 & 21 & 40.79 & 19.65 & 7 & 5.7 & $B$ & Duni & Southern Albanis & Albania \\
\hline 60577 & 34 & & 1985 & 01 & 16 & 23 & 35 & 58 & 40.64 & 19.4 & 6.5 & 5 & $B$ & Duni & South-Westem Albania & Albania \\
\hline 60587 & 27 & & 1988 & 01 & 109 & 01 & 02 & 48 & 41.24 & 19.83 & 7 & 5.7 & $B$ & Duni & Central Albania & Albania \\
\hline
\end{tabular}

In the second column (ns) is the number of scanned Seismograms available for each earthquake

In the third column $(R)$

* = requested by 2 or more national partners

$b=$ before 1895

$1,2,3$, ecc. $=$ events supposed duplicated, please help us to check

Fig. 13. For each project partner a page is active with the list of chosen earthquakes, which allows us to access, by means of the link of the NTERR column the updated situation of the seismograms and the data available for each event.

the potential offered by historical seismograms for reappraising historical earthquakes using modern techniques. The necessary steps for pursuing the above goals are:

1) a well organized data-collection,

2) high resolution digital scanning of the historical material,

3) dissemination of the digital images

4) fostering the growth of a Euro-Mediterranean community on the topic of the processing of the seismograms of the historical earthquakes.

As the SISMOS facility of INGV (see Michelini et al., 2005, for a recent update on its activities) had already set up a scanning laboratory with dedicated personnel (http://sismos.ingv.it), it was agreed that the image-processing activities and the data dissemination should be centralised at the INGV headquarters in Rome, where the SISMOS facility is situated.

The Euroseismos project website (http://storing.ingv.it/es_web/) has been developed and updated by SGA Storia Geofisica Ambiente of
Bologna. Thanks to regular updating of the data, all the partners have been able to follow the project stages (fig. 11) and gain a picture of the information contents available in real-time (figs. 12, 13 e 14). In the various section of the website, the pages are enriched with previous information for the study of the seismograms, archived in the TROMOS database thanks to the recovery and the digitalisation of the complementary documentation (figs.15-17).

By the end of 2007, the project had been capable of collecting 30,000 historical seismograms from 132 observatories from a list of 611 earthquakes chosen by the participants (figs. 13 and 14). The scanned digital images have been assembled in DVD volumes and mailed to the contributing partners. Similarly, all the historical records are viewable interactively at low resolution and can be requested at very high resolution on the «Seismogram Request» Sismos web site.

Throughout the four years of the project, financial support was provided by INGV to SGA. 


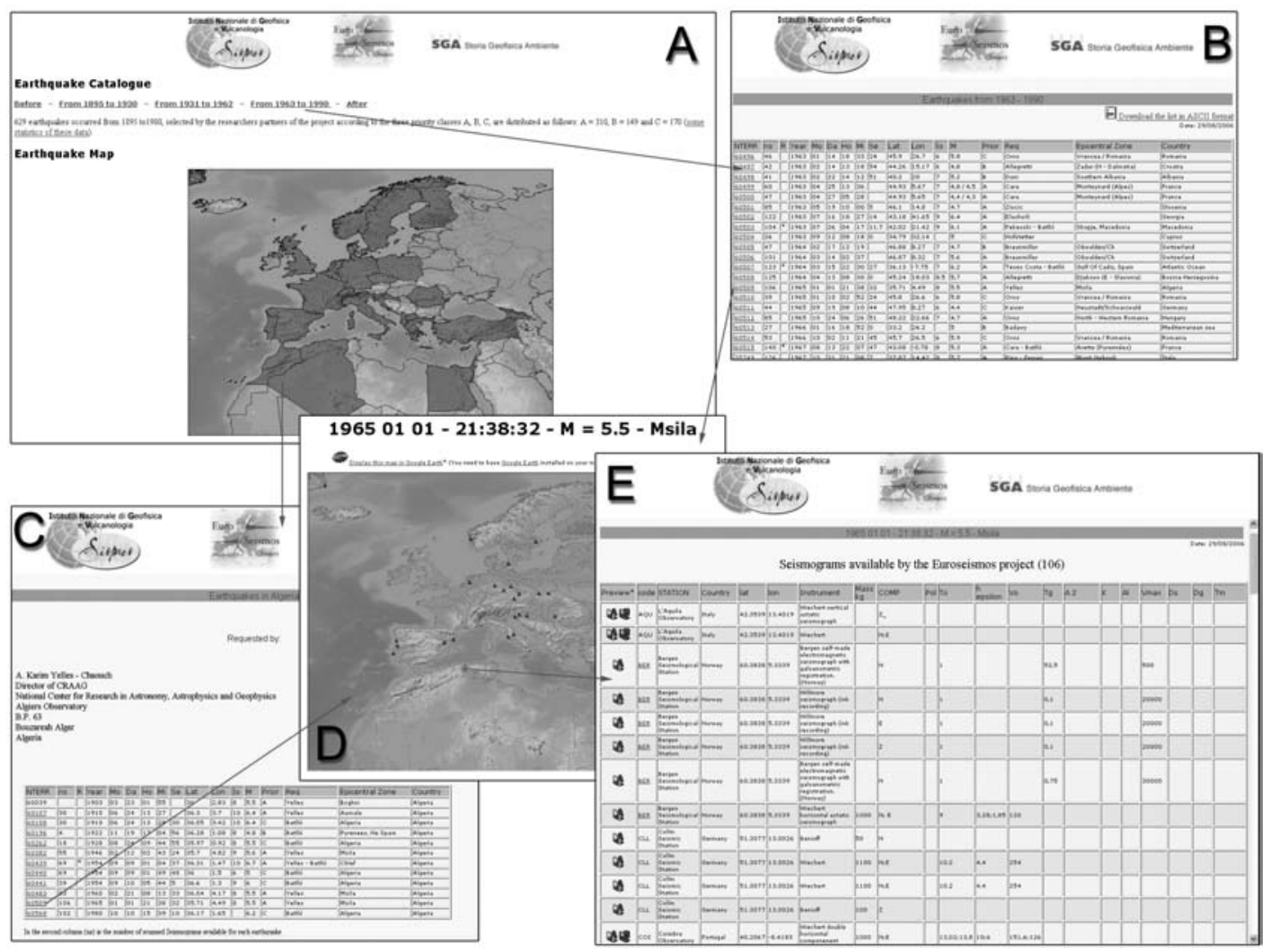

Fig. 14. From the «Main and regional list» section of the ES Website (A), it is possible to access the consultation of the data available for each of the 611 earthquakes chosen by the project partners, both on chronological (Earthquake Catalogue) (B), and geographical grounds (Earthquake Map) (C), in relation to the country in which the epicentres are localised. From both windows it is possible to select the earthquake of interest and visualise an interactive map all the stations where seismograms scans are available in the SISMOS database, besides the epicentre of the event (D). By clicking on one of the sensitive points the list of seismograms available in the SISMOS database for that earthquake is visualised; for each one the main data present in the TROMOS database relating to the observatory and the recording instrument and its constants (E) are reported. By clicking on the icon of the left-hand column of the latter window (E) it is also possible to access a low-resolution preview of the seismograms.

SGA was in charge of gathering and identifying the relevant material, organizing the exchange of materials among the participants and INGV, preparing and managing the Euroseismos web site, and maintaining contacts with the project partners. In addition, the project has greatly benefited from the expertise of the SISMOS personnel for archiving and managing the abundance of digital raster images.
Finally, in September 2005, the «1st Workshop on the Vectorizazion of Historical Seismograms» was held in Grottaminarda, Italy, organized by INGV in collaboration with SGA, during which the Teseo $^{2}$ vectorizer (http://sismos.ingv.it/teseo/, Pintore et al., 2005) was presented and its use explained. About 20 participants from 10 Countries of the Euro-Mediterranean region attended the workshop. 


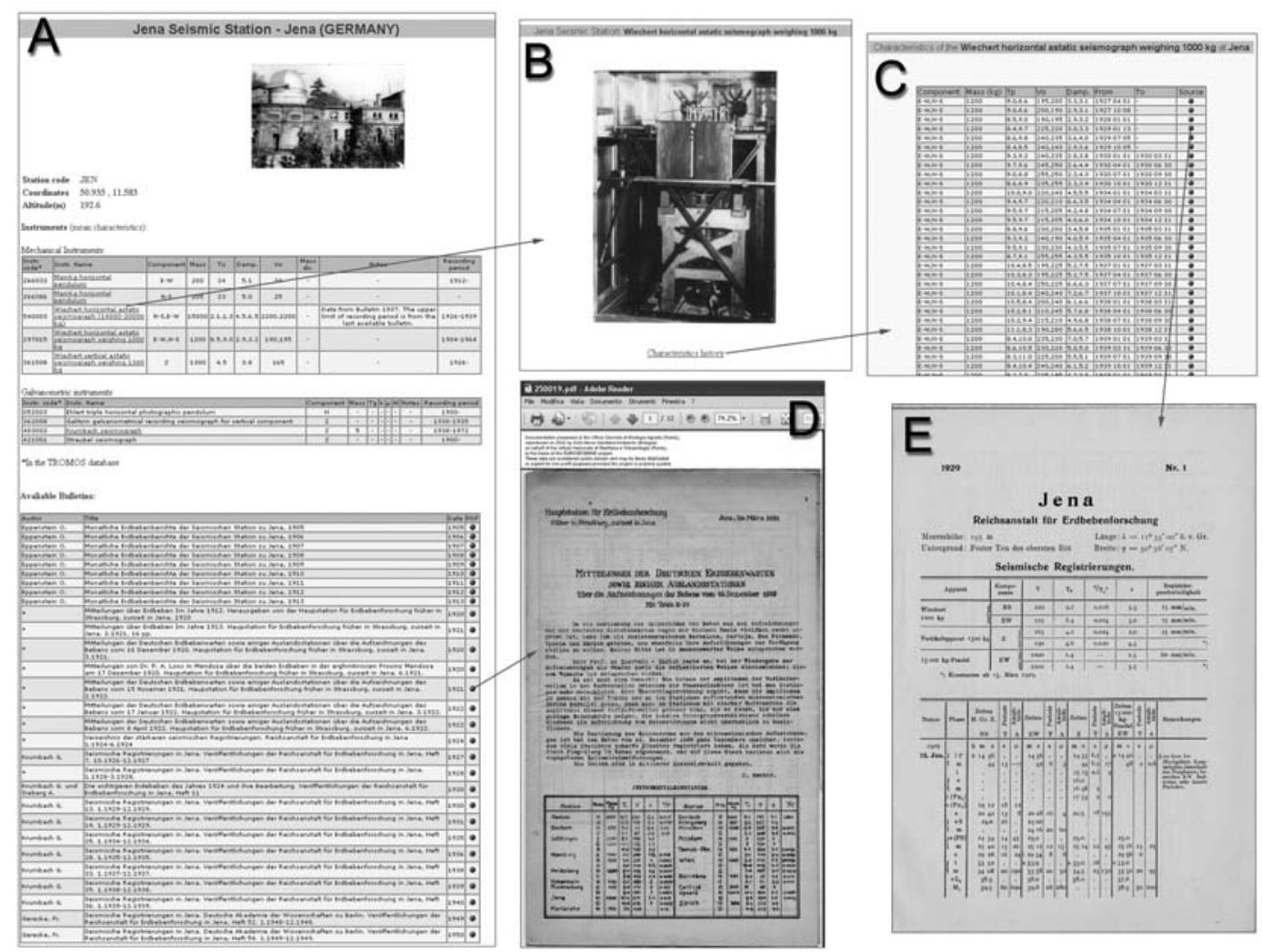

Fig. 15. Example of consultation through the ES website of the complementary documentation relating to the Jena observatory, collected and scanned within the scope of the TROMOS and EUROSEISMOS projects and stored in the TROMOS database. In the main page of the station (A) the following are indicated: name, location, province or region, nation, international code, geographical coordinates and quota. Also present, when available, are observatory photos. The tables relating to the instruments that have worked at the station follow, divided into mechanical and galvanometric. For each instrument the main average constants and the recording period are indicated; by clicking on the name a page opens with the image of the single instrument (B); through a link it is possible to access the page relating to the instruments' seismic constant history (C); for each time-interval the constants refer to, there is a link that enables the viewing of the scan of the single page of the bulletin from which the information has been drawn (D). At the bottom, in the main page of the station (A) the available bulletins are listed in a table, with the indication of the author, the title and the year of the edition; through a link it is possible to open the PDF of the integral raster reproduction of the bulletin.

As explained above, the project has paid special attention to the complementary documentation and has promoted the recovery, digital scanning and dissemination of those materials. Seismic bulletins, station books, handwritten notes, scientific correspondence, copies of seismograms amount to a complementary documentation to the seismic recordings have a great bearing on their improved interpretation. This kind of documentation, being the subject of recovery and reproduction within the TROMOS project in Italy, would also be the subject of special attention in EUROSEISMOS (figs. 15 and 16). In the various sections of the ES web site a lot of precious information is made available to the researchers relating to the ob- 


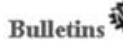

Consultation by Country and download of bulletins reproduced in the frame of Euroseismos project are available by the map below

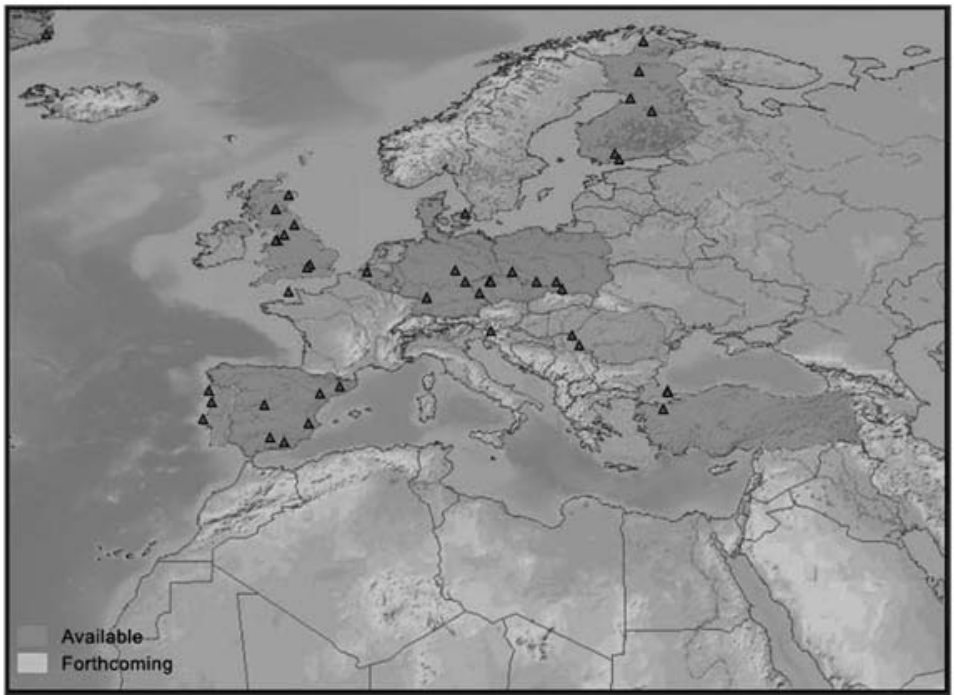

Fig. 16. Euroseismos website: Geographic access by country to the seismic bulletins of the different observatories. By clicking on the map it is possible to ace the list of bulletins collected during the project for each country. From this list it is possible to open the PDF file of the integral raster reproduction of each single bulletin.

servatories and the instrumental constants and their change in time, coming from such a complementary documentation and archived in the TROMOS database, both during the project and during the previous 17 years.

Within the framework of the EUROSEISMOS the project bulletins of the International Seismological Summary (ISS) from 1918 to 1963, for a total of over 39,000 pages have also been scanned and collated.

The original bulletins of the International Seismological Summary (ISS) from 1918 to 1939 have been obtained thanks to funding provided by the US National Science Foundation through grant EAR-9725140 (Villaseñor et al., 1997) and have been scanned and collected by SGA Storia Geofisica Ambiente (Bologna) thanks to funding provided by the Istituto Nazionale di Geofisica e Vulcanologia (Rome).

The scanned images of the bulletins of the International Seismological Summary (ISS) from 1940 to 1963 have been obtained as part of a global earthquake relocation project (Villaseñor et al., 1997) initiated with funding from the US National Science Foundation through grant EAR-9725140 and collected by SGA Storia Geofisica Ambiente (Bologna) on behalf of the Istituto Nazionale di Geofisica e Vulcanologia (Rome).

A dedicated section of the Euroseismos site allows for the online consultation of the single pages of the ISS bulletins or, alternatively, the download of each and every whole bulletin in PDF (fig. 17).

The updating of the EUROSEISMOS site is guaranteed by a complex automatic procedure devised by SGA, which starts from the data relating to the scanned seismograms coming from the SISMOS database. That procedure searches in the TROMOS Database for all the information available relating to the station and the recording instruments and automatically 


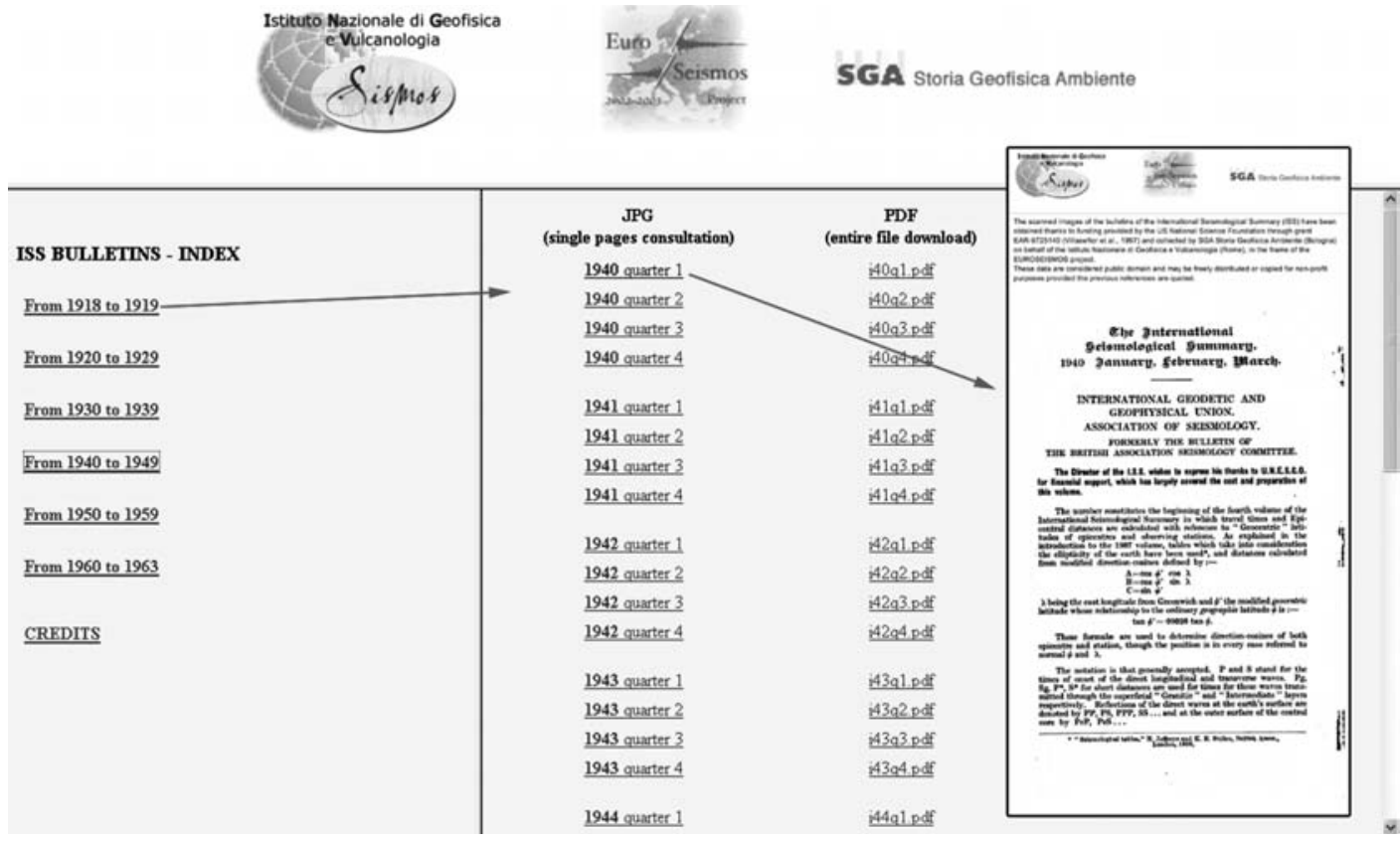

Fig. 17. Section of the ES web site in which it is possible to consult the ISS bulletins from 1918 to 1963 page by page and download them wholly in PDF.

generates the HTML pages for the consultation of the ES site and illustrated in this Chapter (fig. 18).

\section{Macroseismic questionnaires}

In 1985, during its research, SGA came across a copious unpublished historical scientific documentation in the 16th century loft spaces of the UCEA, which for years had been used merely as stock rooms. This documentation consisted of macroseismic questionnaires, seismograms, meteorological questionnaires and unpublished documentation of seismological and meteorological interest. The documentation of seismological interest was given out on study loan to SGA by the UCEA management. The operation achieved a dual objective: that of saving this material from the risk of decay and dispersion, and that of making avail- able the scientific contents of the documentation for research into historical seismology and the history of seismology.

The macroseismic questionnaires represent an original documentary format, fundamental in the reconstruction of the historical seismic scenarios. These are special pre-formatted questionnaires that were filled in when earthquakes occurred and then centralised at the Central Office of Meteorology and Geodynamics (subsequently at the ING). Notwithstanding their peculiarity, these documents belong to the genre of scientific letters.

In Italy there are two important archives of macroseismic questionnaires: the one cited above (1871-1900), preserved at the Ufficio Centrale di Ecologia Agraria (Central Office of Agrarian Ecology of Rome - UCEA, now CSA-CRA), and the other preserved at the INGV that involves the subsequent period up to the present-day, with a few gaps in the 1970s. 

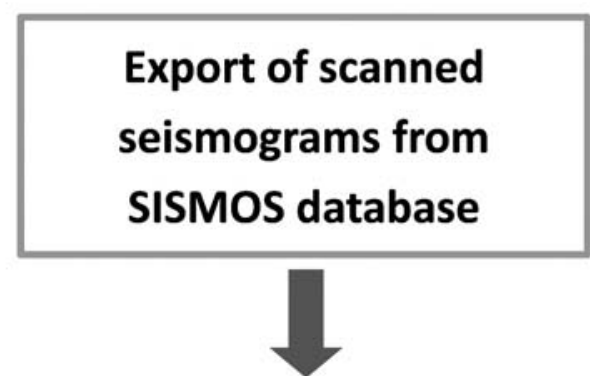

Data of Observatories, instruments, constants from TROMOS database

\section{Tool for automatic generation}

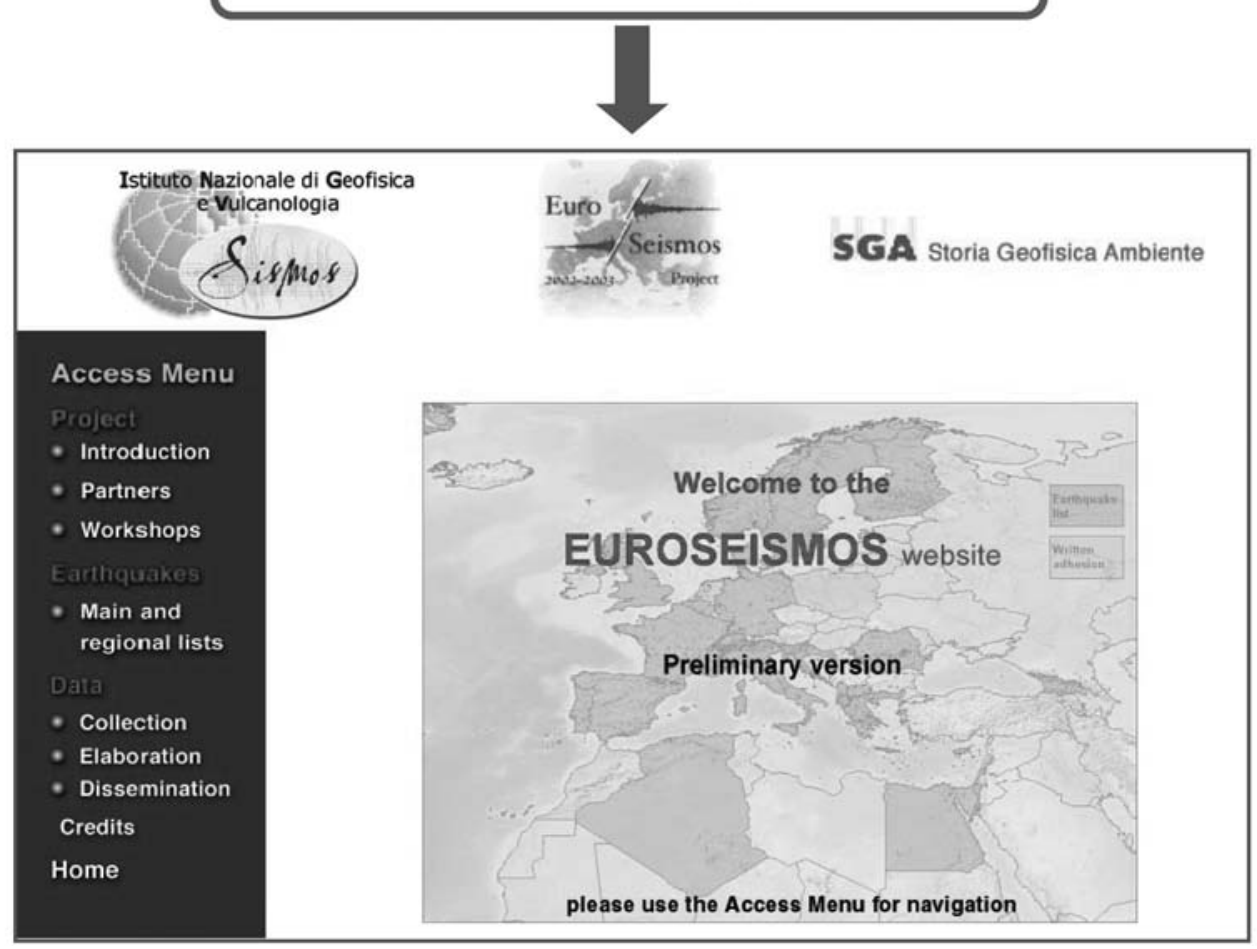

Fig. 18. Simplified scheme of the procedure for updating the EUROSEISMOS site.

In the spring of 2003, on behalf of INGV (Istituto Nazionale di Geofisica e Vulcanologia), SGA completed the digital scanning of the entire archive containing the macroseismic questionnaires (over 37,000 documents) of the Ufficio Centrale di Ecologia Agraria of Rome (where the first Italian public geodynamic service was founded in 1887).

The documents that make up the UCEA archive have been submitted to colour scanning at a resolution of $300 \mathrm{dpi}$. The reproduction has involved all of each document. In order to guar- 

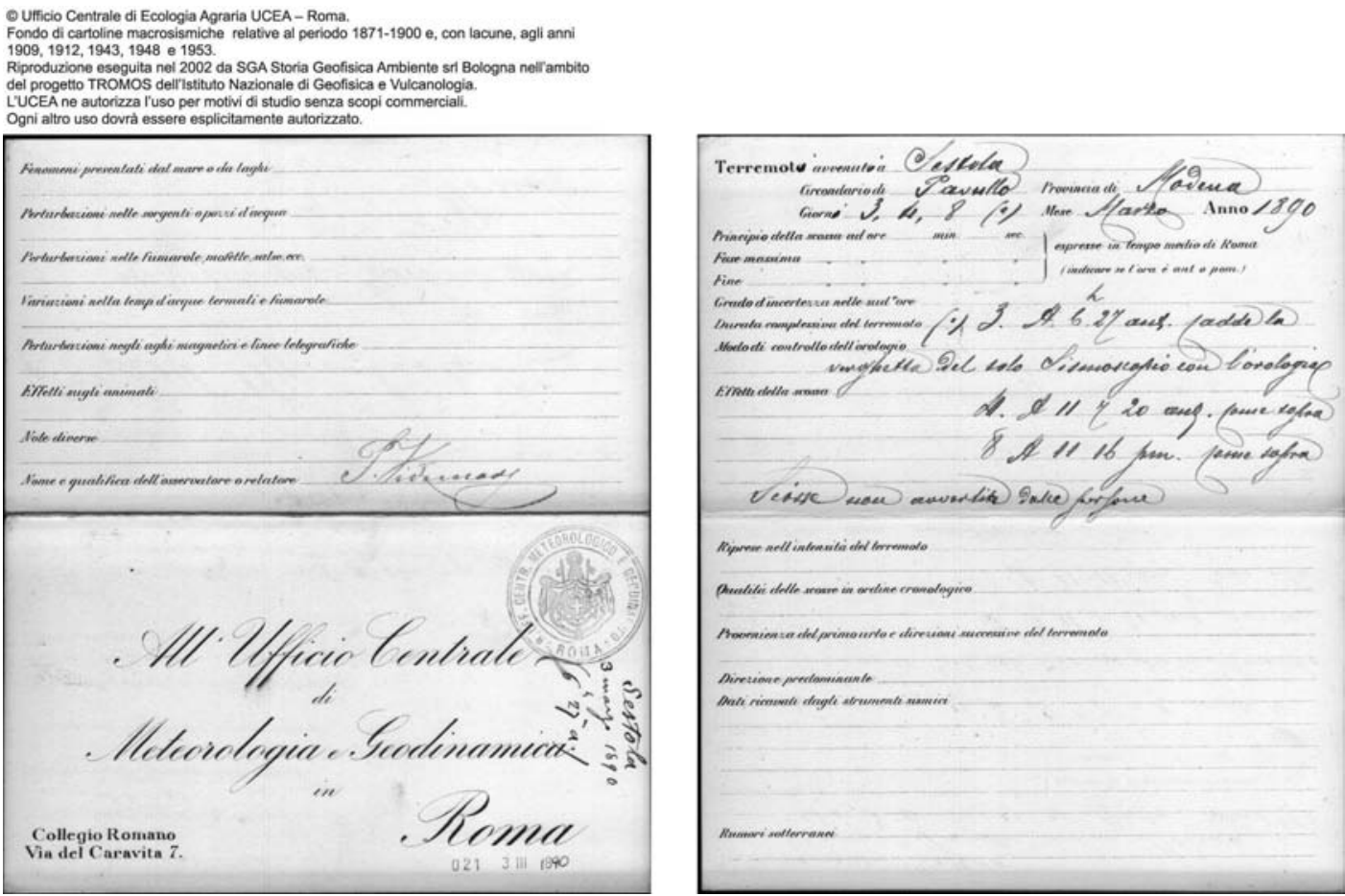

Fig. 19. Example of PDF file with the front and back images of a macroseismic questionnaire. The heading reports the institution owning the documents, the institution promoting the reproduction and the use of the documentation reproduced.

antee a user friendly and complete consultation the 76,244 images have been set up in PDF files that maintain the uniqueness of the different documents. So a PDF file with the back and front images of the document identifies a macroseismic questionnaire, while a paper consisting of several pages has been laid out in a PDF file containing all the pages of the report. This processing has produced 37,467 file-documents.

As for the other similar reproduction initiatives performed within the scope of the TROMOS project and in compliance with the rules for the use of archival materials, each PDF page presents a heading (fig. 19) that cite the body owing the documents, the body promoting its reproduction and the terms of use of the documentation reproduced.
The single images were transferred to filedocuments in PDF complete with headings by means of a single automatic procedure performed by software, developed in $\mathrm{C}++$ language and specifically designed.

The 37,467 PDF files thereby obtained of the digital scans of the macroseismic cards of the UCEA Archive are all collected in 10 DVDs that altogether occupy over 32 Gigabytes.

The numbering of the single PDF files and their organisation inside the folders largely follows the order present in the paper archive at the time of the scanning which, apart from some exceptions pointed out here, also represents the chronological order.

An HTML index (fig. 20), created by means of automatic procedures specifically developed for this job, allows the chronological consulta- 


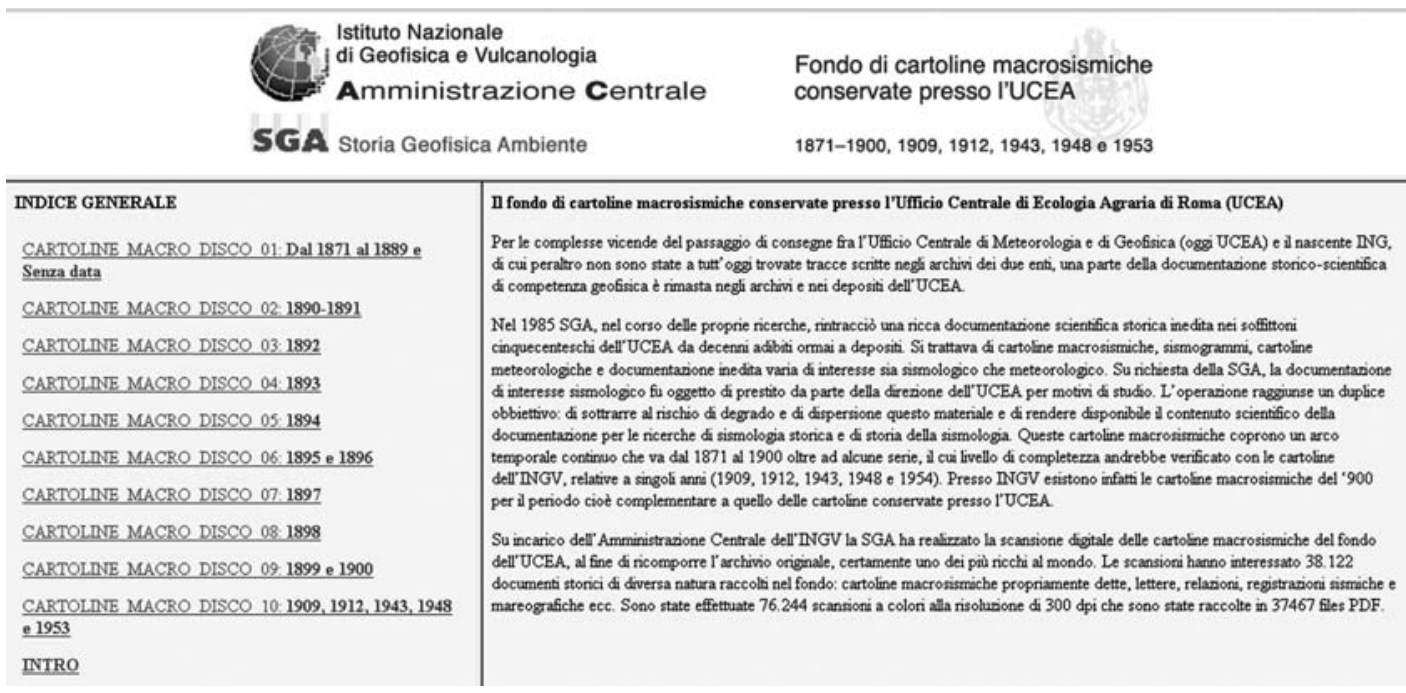

Fig. 20. Initial HTML page (Home) for the chronological consultation of the digital of the macroseismic questionnaires. In the top frame the project credits are given; in the one on the left there is a general index with the links for the navigation within the Archive; in the one on the right-hand side, the history of the Archive is concisely told, from its birth to the digital scanning in 2003.

tion, by year and month, of the whole. The advantage of a consultation by means of an HTML index is first and foremost its accessibility through any browser, irrespective of the platform and the operating system. This form of data organisation facilitates the online digital publication of the macroseismic questionnaires already reproduced and also opens up interesting applicative prospects or other analogues archives present in the seismological research bodies both in Italy and abroad.

Given the territorial nature of the seismic event, an application has also been developed that allows us to consult the digital files of the macroseismic questionnaires on a geographical basis. This application has so far been tested on some sample events, and not on the whole file, in that for it to work properly it is necessary to carry out a preliminary task of re-coding the single PDF files, which, given the size of the file, calls for a large amount of time. After a thorough job of comparing the cards with the toponomastic catalogues and the earthquake catalogue, the PDF files are renamed on the grounds of a pair of codes that univocally identify the location of origin of the document (NLOC) and the seismic event whose effects are being described (NTERR).

Subsequent to such a codification, it becomes possible to automatically create, through a MAPINFO PROFESSIONAL tool developed using MAPBASIC language, an interactive map for each earthquake (fig. 21), which visualises all the locations from which the questionnaires had been sent, thus allowing the geographic access to the documents.

The cartographic tool developed first of all generates the earthquake list on the grounds of the NTERR codes present in the file names, taken only once. For each line of that list it identifies the NLOC associated to the NTERR and it extracts from the database the basic information relating to the seismic event (intensity and epicentral localisation) and the different locations (geographic coordinates).

The individual maps of the distribution of 


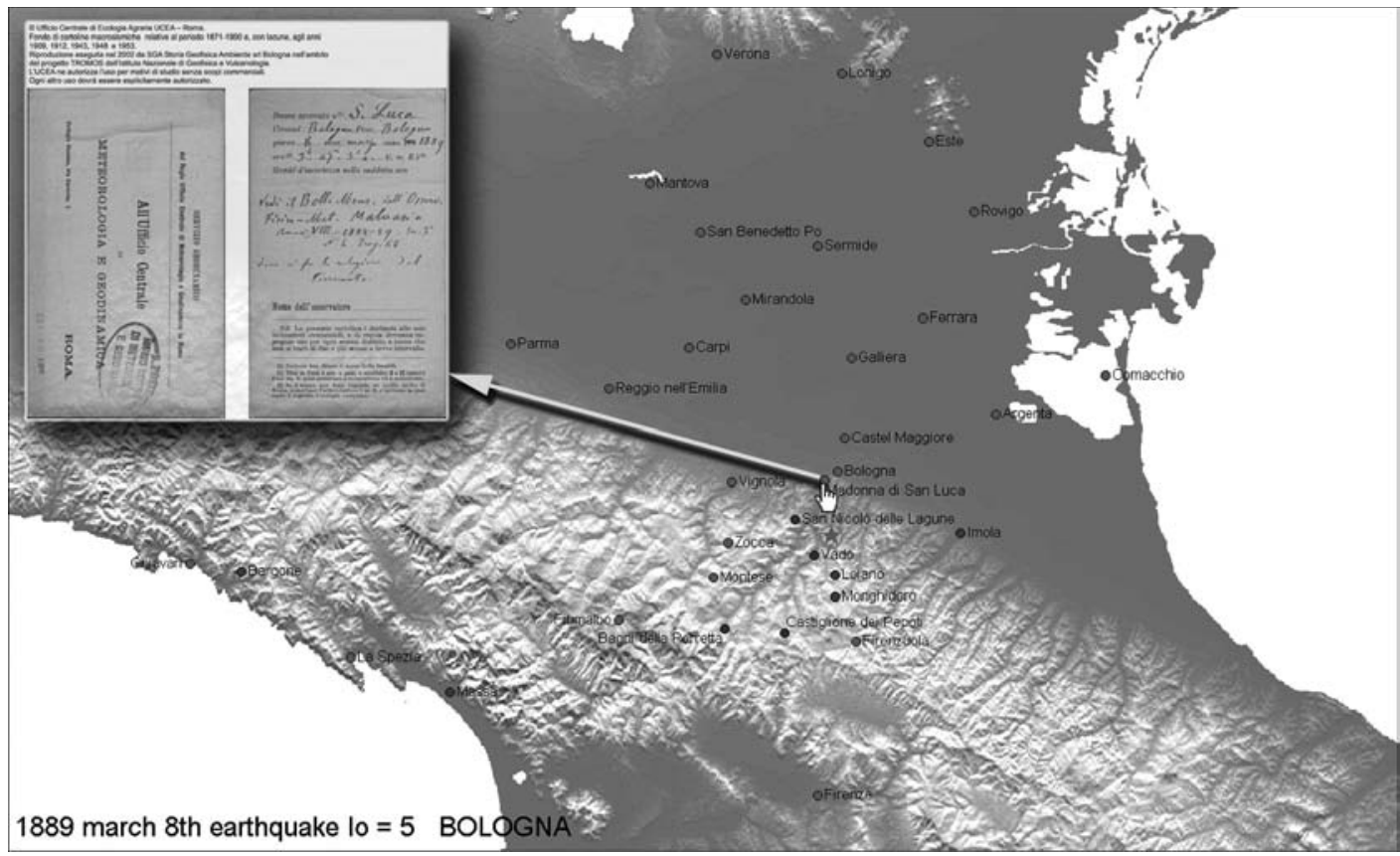

Fig. 21. Example of interactive map allowing to geographically access the consultation of the digital file of the macroseismic questionnaires. By clicking on the map the documents relating to each location can be visualised and interpreted.

the information for each event are thus created. Thanks to the NLOC-NTERR codification it is also possible, by means of a special and purpose-designed Hot-Link key to access the documents directly from the map itself.

\section{Conclusions}

The methodological approach followed by SGA in the valorisation of historical scientific documentary heritage from 1986 to the present, based on the application of information technology tools that have enabled us to achieve a rigorous treatment and study of documents, is always oriented to such techniques and solutions that offer widescale accessibility to the documentation and that allow a modern form of dissemination.

The methodological approach followed by
SGA is also oriented to creating a new disciplinary community dedicated to studying the history of the earth sciences. The cases we have reported here comprise some possible examples of new forms of interaction between research in historical seismology and the techniques used to encourage the dissemination and study of historic scientific documentation.

\section{REFERENCES}

Boschi, E., E. Guidoboni, G. Ferrari, D. Mariotti, G. VALENSISE and P. GASPERINI (2000): Catalogue of Strong Italian Earthquakes from 461 B.C. to 1997, Introductory texts and CD-ROM, Version 3 of the Catalogo dei Forti Terremoti in Italia, Annali di Geofisica, 43 (4), 609-868.

FERRARI, G. (1992): The TROMOS project 1990-1: a laboratory for the history of seismology, in Two hundred years of seismic instruments in Italy 1731-1940, edited by G. Ferrari, (ING-SGA, Bologna), 14-18. 
FERRARI, G. (1997): Cultural and scientific value of seismology's heritage in Europe: why and how to preserve, Proceeding of the Workshop: Historical Seismic Instruments and Documents: a Heritage of Great Scientific and Cultural Value, edited by G. FerRARI, May 16th to 18th, 1994 Walferdange (Grand-Duchy of Luxembourg), Conseil de l'Europe, Cahiers du Centre Européen de Géodynamique et de Séismologie, vol. 13, 1 30.

FERRARI, G. (2002): Census, filing and elaboration of scientific letters in the Earth sciences, Nuncius, 17 (1), $307-$ 320.

Guidoboni, E., G. Ferrari, D. Mariotti, A. Comastri, G. TARABUSI and G. VALENSISE (2007): CFTI4Med, Catalogue of Strong Earthquakes in Italy (461 B.C.-1997) and Mediterranean Area (760 B.C.-1500), INGV-SGA, Available from http://storing.ingv.it/cfti4med/.
KANAMORI, H. (1988): Importance of historical seismograms for geophysical research, in Historical Seismograms and earthquakes of the world, edited by W.H.K. LeE, H. Meyers and K. ShimazaKi, (Academic Press), 16-33.

Michelini, A., B. De Simoni, A. Amato and E. Boschi (2005): Collecting, Digitizing, and Distributing Historical Seismological Data, Eos Trans. AGU, 12 July 2005, 86 (28).

Pintore, S., M. Quintiliani and D. Franceschi (2005): Teseo: A vectoriser of historical seismograms, Computers \& Geosciences, 31, 1277-1285.

Villaseñor, A., E.A. BeRgMan, T.M. Boyd, E.R. ENGDAhal, D.W. Frazier, M.M. Harden, J.L. Orth, R.L. PARKES and K.M. SHEDLOCK (1997): Tovard a comprehensive catalog of global historical seismicity, Eos Trans. AGU, $\mathbf{7 8}$ (50), 581, 583, 588. 